\title{
Fabrication of a tellurite hollow core optical fiber with six non-touching cladding air holes
}

\author{
Hoang Tuan TONG ${ }^{1, \dagger}$, Nobuhiko NISHIHARAGUCHI ${ }^{1}$, Takenobu SUZUKI $^{1}$ and Yasutake OHISHI $^{1}$ \\ ${ }^{1}$ Research Center for Advanced Photon Technology, Toyota Technological Institute, \\ 2-12-1 Hisakata, Tempaku, Nagoya 468-8511, Japan
}

\begin{abstract}
We experimentally demonstrate for the first time a successful fabrication of a new tellurite hollow core optical fiber which has 6 non-touching air holes in the cladding. This is because it is known from the simulation that when the two nearby cladding air-holes connect to each other, the confinement loss in the core will be high. New tellurite glass is developed to improve the optical and thermal properties and the light transmission properties from 0.4 to $2.4 \mu \mathrm{m}$ are studied experimentally. In addition, the calculation shows that high transmission bands and low transmission bands which locate alternately in the measured transmission spectrum correspond to the effects of resonant reflection and anti-resonant reflection.

(C2019 The Ceramic Society of Japan. All rights reserved.
\end{abstract}

Key-words : Hollow core fiber, Microstructured optical fiber, Fiber fabrication and characterization

[Received July 8, 2019; Accepted September 19, 2019]

\section{Introduction}

Due to the air-guiding characteristics of the air-core, hollow core optical fibers (HCOFs) can give rise to many unique properties which cannot be realized by using conventional solid fibers such as high optical power delivery, ${ }^{1)}$ high damage threshold, ${ }^{1)}$ low loss levels ${ }^{2), 3)}$ and broad bandwidth from vacuum ultraviolet to the $\mathrm{NIR}^{4)}$ up to the mid-IR region ${ }^{5)}$ or even terahertz range. ${ }^{6)}$ HCOFs can confine the electromagnetic field inside the central air-core ${ }^{7)}$ where lights can be guided by photonic bandgap effect ${ }^{8)}$ due to the presence of the periodic air-hole microstructure in the cladding or by antiresonant reflection effect ${ }^{9)}$ which enables light confinement in a medium with a lower refractive index than that of its surroundings. ${ }^{10), 11)}$

Recently, hollow core antiresonant fibers ${ }^{11)-14)}$ have been widely studied because it is not necessary to have a complicated air-hole structure in the cladding but the first ring of air holes mainly determines the guiding properties. ${ }^{15)}$ It is demonstrated that the antiresonant reflection mechanism allows a much broader spectral transmission than that achieved in photonic bandgap fibers ${ }^{16), 17)}$ and low loss transmission bands, even in a mid-IR wavelength region $(\lambda>4 \mu \mathrm{m})$, can be obtained by using one ring of air hole despite of very high material losses of silica. ${ }^{15)}$ Due to their superior properties, HCOFs have many potential applications including data communications, ${ }^{18), 19)}$ optical data transmission, ${ }^{20)}$ terahertz propagation, ${ }^{6), 21), 22)}$ power beam delivery for industrial applica-

Corresponding author: H. T. Tong; E-mail: tonghoangtuan@ gmail.com tions such as cutting, welding, and engraving, ${ }^{1)}$ medical applications ${ }^{23), 24)}$ and chemical sensing. ${ }^{25)-27)}$

A tellurite HCOF with a large hexagonal hollow core in the center was demonstrated in our previous work. ${ }^{28)}$ However, the two adjacent air-holes in the cladding connected to each other. In this work, a new tellurite HCOF with 6 non-touching air holes in the cladding is realized. The fiber is successfully fabricated and its transmission spectrum is experimentally measured from 0.4 to $2.4 \mu \mathrm{m}$. By our calculation, it can be confirmed that high transmission bands and low transmission bands which locate alternately in the measured transmission spectrum are due to the effect of antiresonant reflection and resonant reflection, respectively.

\section{Fiber development}

\subsection{Previous work}

Figure 1 show a tellurite HCOF which was demonstrated in our previous work. ${ }^{28)}$ The fiber had a large hexagonal hollow core surrounded by a microstructure of smaller air holes in the cladding. ${ }^{28)}$ The walls of two adjacent cladding air holes touched each other and the width of the touching area was about 1.2 to $1.5 \mu \mathrm{m}$. Although it was proved in our experiments that supercontinuum light can be propagated in the air-core of the fiber by the fundamental mode and the $1 \mathrm{st}$ order mode, ${ }^{28)}$ the measured output spectrum from 0.4 to $2.4 \mu \mathrm{m}$ after a $7-\mathrm{cm}-$ long fiber was narrow and noisy as shown in Fig. 2.

This feature can be attributed to the high transmission loss due to the existence of the touching area. The touching area between two cladding air holes can be considered as additional optical resonators. ${ }^{7)}$ They make the density 

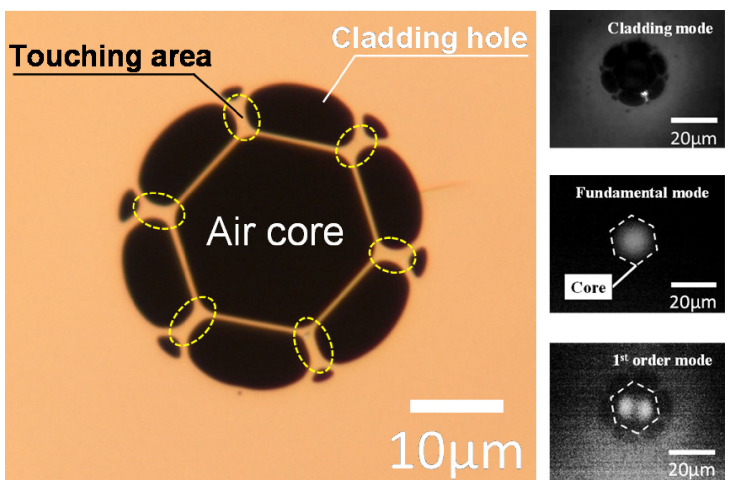

Fig. 1. Cross-sectional image of the tellurite HCOF with touching air-hole structure in the cladding and intensity distribution profiles of modes which can be propagated in a 7-cm-long the fiber. $^{28)}$

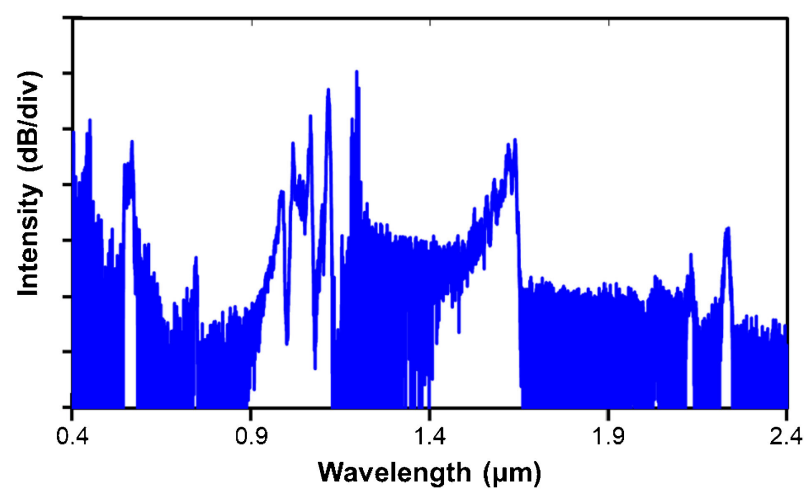

Fig. 2. Measured output spectrum after supercontinuum light was launched into a 7-cm-long tellurite HCOF.

of electromagnetic states in the cladding ${ }^{7)}$ and the leakage loss of the propagating mode ${ }^{13)}$ rapidly increase. Accordingly, they cause high optical loss in the transmission spectrum. To reduce this transmission loss, it is necessary to develop new tellurite hollow-core fiber whose structure does not include those touching area.

\subsection{Glass material developments}

New tellurite glasses based on $\mathrm{TeO}_{2}, \mathrm{ZnO}, \mathrm{Li}_{2} \mathrm{O}$ and $\mathrm{Bi}_{2} \mathrm{O}_{3}$ were developed by systematically investigating the influence of the mole percentage of each component. Among them, the $76.5 \mathrm{TeO}_{2}-6 \mathrm{ZnO}-11.5 \mathrm{Li}_{2} \mathrm{O}-6 \mathrm{Bi}_{2} \mathrm{O}_{3}$ (TZLB) glass was chosen as a potential glass material for the fiber fabrication because of its good optical and thermal properties. Its transmission spectrum from 0.2 to $10 \mu \mathrm{m}$ was measured by an ultraviolet-visible spectrometer (Perkin Elmer, Lambda 900) and an fourier transform infrared spectroscopy spectrometer (Perkin Elmer, Spectrum 100) and was shown in Fig. 3. As compared to the result in our previous work, ${ }^{28)}$ the transmission spectrum in this work was improved and expanded further to long wavelength side although the same TZLB glass composition was used. The reason can be attributed to the modification of the melting process. In this work, the powders to make glass samples were preheated in an hour at $550^{\circ} \mathrm{C}$ and then were completely melted in one more hour at

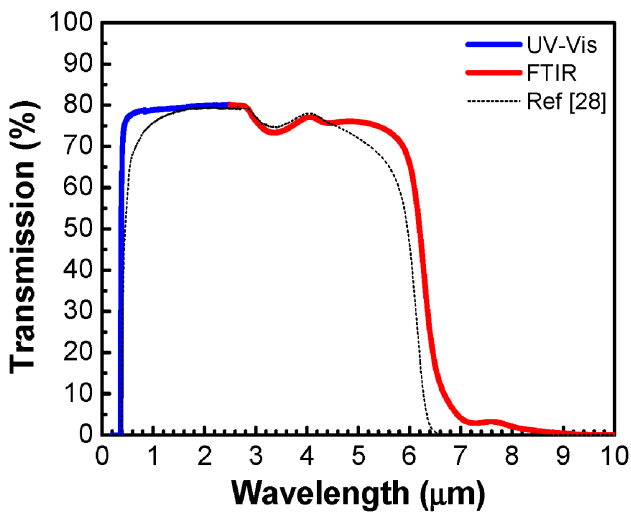

Fig. 3. Measured transmission spectra of the TZLB 76.5 $\mathrm{TeO}_{2}-$ $6 \mathrm{ZnO}-11.5 \mathrm{Li}_{2} \mathrm{O}-6 \mathrm{Bi}_{2} \mathrm{O}_{3}$ glass (bolded line) and the tellurite glass in our previous work ${ }^{28)}$ (dashed line).

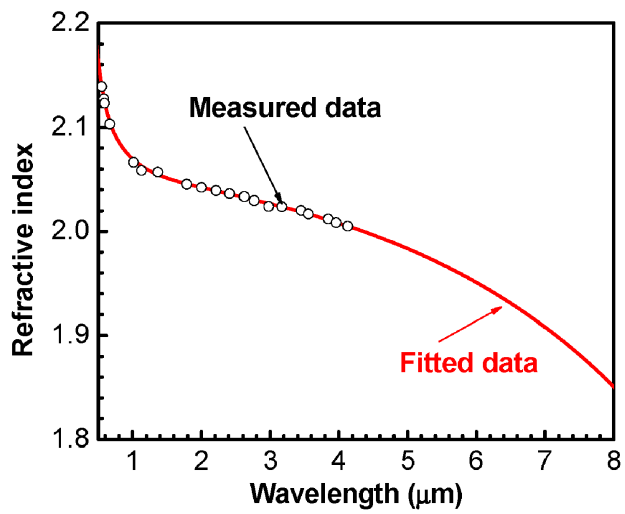

Fig. 4. Refractive index dispersion of the TZLB 76.5 $\mathrm{TeO}_{2}-$ $6 \mathrm{ZnO}-11.5 \mathrm{Li}_{2} \mathrm{O}-6 \mathrm{Bi}_{2} \mathrm{O}_{3}$ glass.

Table 1. Sellmeier coefficients of the TZLB glass $\left(76.5 \mathrm{TeO}_{2}-\right.$ $6 \mathrm{ZnO}-11.5 \mathrm{Li}_{2} \mathrm{O}-6 \mathrm{Bi}_{2} \mathrm{O}_{3}$ )

\begin{tabular}{|c|c|c|c|c|}
\hline \multirow{2}{*}{ Material } & \multicolumn{4}{|c|}{ Sellmeier coefficients } \\
\hline & & $i=1$ & $i=2$ & $i=3$ \\
\hline \multirow{2}{*}{ TZLB } & $A_{i}$ & 3.1773 & 0.0028 & 2.5571 \\
\hline & $L_{i}$ & 0.1827 & 0.4015 & 16.7426 \\
\hline
\end{tabular}

$850^{\circ} \mathrm{C}$ instead of $900^{\circ} \mathrm{C}$ in our previous work. The whole process took place inside an electric furnace purged by dried oxygen and argon gases to greatly suppress the effect of moisture contamination.

The refractive index dispersion of the developed TZLB glass from 0.5 to $4.1 \mu \mathrm{m}$ was obtained by using a triangular TZLB glass prism and the minimum deviation method. ${ }^{29)}$ The measured refractive index was fitted to the Sellmeier equation ${ }^{30), 31)}$ as given by Eq. (1). Both of them are plotted in Fig. 4 and the Sellmeier coefficients are shown in Table 1.

$$
n^{2}(\lambda)=1+\sum_{i=1}^{3} \frac{A_{i} \lambda^{2}}{\lambda^{2}-L_{i}^{2}}
$$

About $20 \mathrm{mg}$ powder of the developed TZLB glass was heated to $600^{\circ} \mathrm{C}$ in a platinum pan at a rate of $10 \mathrm{~K} / \mathrm{min}$ under a nitrogen gas atmosphere by a differential scanning 


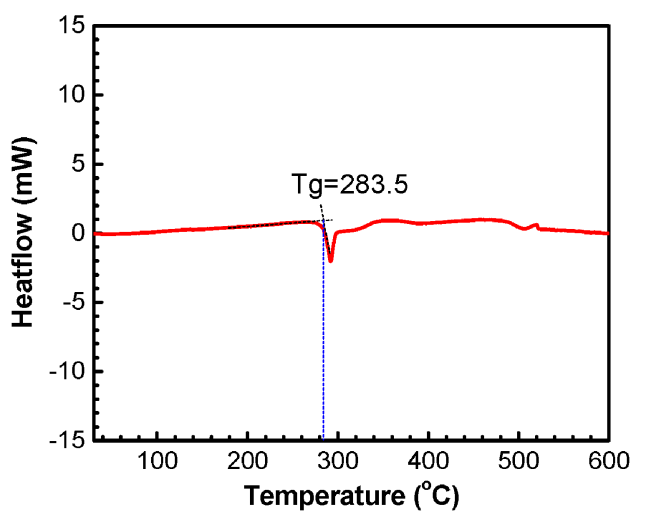

Fig. 5. DSC measurement result of the TZLB $76.5 \mathrm{TeO}_{2-}$ $6 \mathrm{ZnO}-11.5 \mathrm{Li}_{2} \mathrm{O}-6 \mathrm{Bi}_{2} \mathrm{O}_{3}$ glass from room temperature to $600^{\circ} \mathrm{C}$.

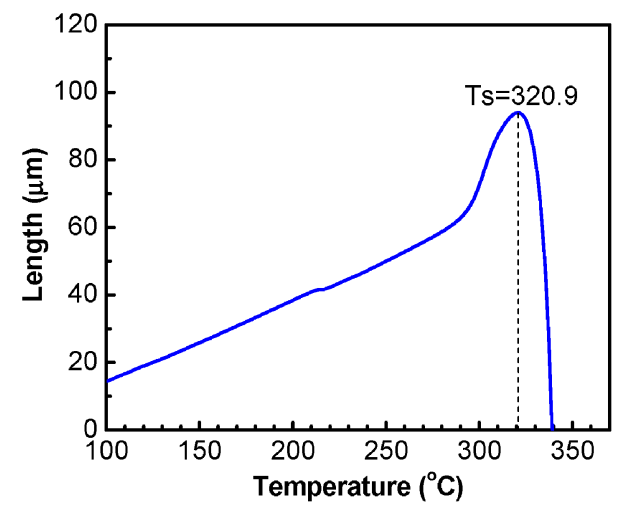

Fig. 6. TMA measurement result of the TZLB $76.5 \mathrm{TeO}_{2-}$ $6 \mathrm{ZnO}-11.5 \mathrm{Li}_{2} \mathrm{O}-6 \mathrm{Bi}_{2} \mathrm{O}_{3}$ glass from 100 to $350^{\circ} \mathrm{C}$.

calorimetry (DSC) system (Rigaku, Thermo Plus DSC 8270 ) to study glass thermal properties. The same amount of $\mathrm{Al}_{2} \mathrm{O}_{3}$ powder was used as the reference sample. The glass transition temperature $\left(\mathrm{T}_{\mathrm{g}}\right)$ at $283.5^{\circ} \mathrm{C}$ can be calculated from the DSC curve shown in Fig. 5. During this heating process, crystallization did not occur as can be understood by the DSC curve. It can be mentioned that our developed TZLB glass has high thermal stability and is suitable for fiber fabrication.

In addition, the glass thermal expansion from 200 to $400^{\circ} \mathrm{C}$ was measured by a thermal mechanical analysis (TMA) system (Rigaku, Thermo Plus TMA 8310) and shown in Fig. 6. The softening temperature $T_{\mathrm{s}}$ was found about $320.9^{\circ} \mathrm{C}$. Above this temperature, the developed TZLB glass becomes soft enough and can be drawn into fiber.

\subsection{Fiber development}

Figure 7 shows schematic images of tellurite HCOFs with non-touching air-hole structure in the cladding. They were used to numerically study the impacts of structural parameters on the fiber performance. Tellurite HCOFs in Fig. 7 are only different in the number of air holes $(N=5$, 6 and 7) in the cladding. The inner diameter of the fiber was $110 \mu \mathrm{m}$, the diameter and the wall thickness of each air hole were 27.5 and $2.79 \mu \mathrm{m}$, respectively. The Comsol

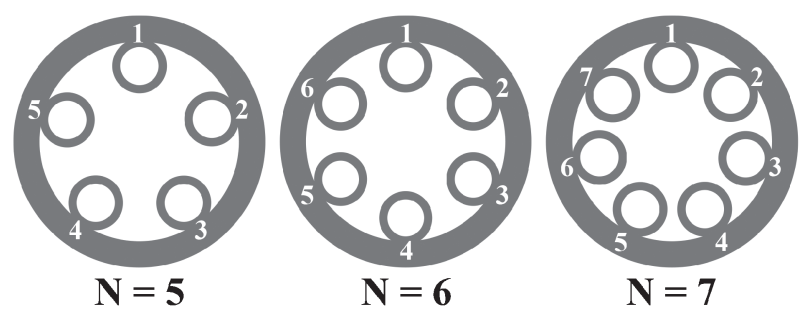

Fig. 7. Schematic image of tellurite HCOFs with non-touching air-hole structure in the cladding and different number of air holes $(N=5,6$ and 7$)$.

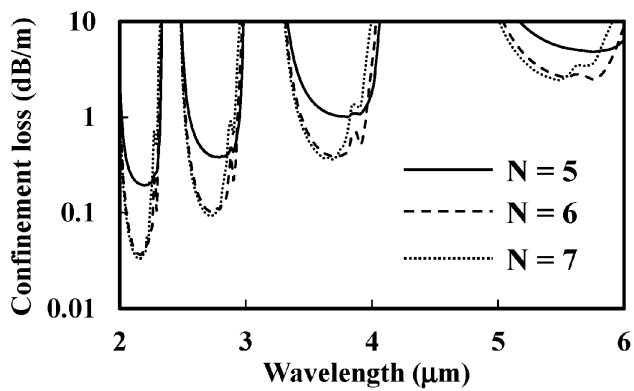

Fig. 8. Calculated confinement loss spectra for the fundamental modes of tellurite fiber in Fig. 7 with different number of air holes $(N=5,6$ and 7$)$.

Multiphysics software, the finite element method (FEM) and the perfectly-matched (PM) boundary condition were used for the calculation of confinement loss and modal intensity distribution. The mesh resolution was automatically optimized to maintain the calculation accuracy and reduce the calculation time. However, the largest mesh size was equal to $0.25 \mu \mathrm{m}$ which is equal to $1 / 8^{32)}$ of the shortest wavelength of the wavelength range from 2 to $6 \mu \mathrm{m}$.

Figure 8 shows the $N$ dependence of the confinement loss calculated for the fundamental modes in the tellurite HCOFs by the solid line $(N=5)$, the dashed line $(N=6)$ and the dotted line $(N=7)$. As can be seen, the confinement loss in four wavelength bands located from 2 to $6 \mu \mathrm{m}$ was less than $10 \mathrm{~dB} / \mathrm{m}$. The confinement loss becomes much lower when $N$ is larger than 5 , but it slightly increases when $N$ is larger than 6 .

Images of the fundamental mode in tellurite HCOFs with non-touching and touching air-hole structure were simulated and shown in Fig. 9(a). In addition, it can be seen that when the gap between two adjacent air holes disappears, their walls connect to each other forming nodes where the mode field can reside. 7),33),34) Due to these coupling modes, the confinement loss is large and the transmission spectrum is degraded. The calculated intensity distribution of the leaky mode in the glass wall for touching air-hole structure is also plotted in Fig. 9(a). To quantitatively show that non-touching air-hole structure has lower loss than touching air-hole structures, the confinement loss spectra for the fundamental modes of those structures were calculated when $N=6$ and they are shown in Fig. 9(b). It can be understand clearly from Fig. 9(b) 


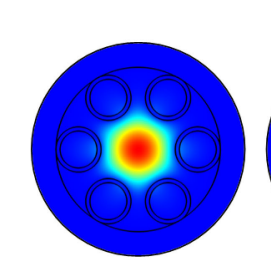

Non-touching air-hole structure
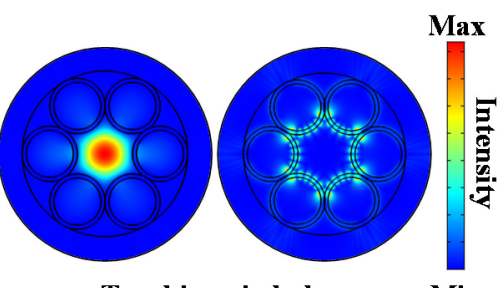

Touching air-hole structure
Fig. 9(a). Calculated intensity distribution of the fundamental mode in the air core for non-touching air-hole structure (left) and touching air-hole structure (center) when $N=6$. In addition, the calculated intensity distribution of the leaky mode in the glass wall for touching air-hole structure (right) is shown.

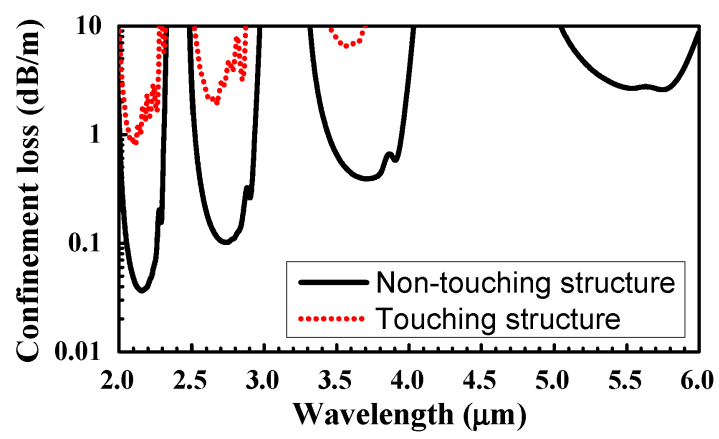

Fig. 9(b). Calculated confinement loss spectra for the fundamental modes of non-touching air-hole structure and touching air-hole structure when $N=6$ (Fig. 9(a)).

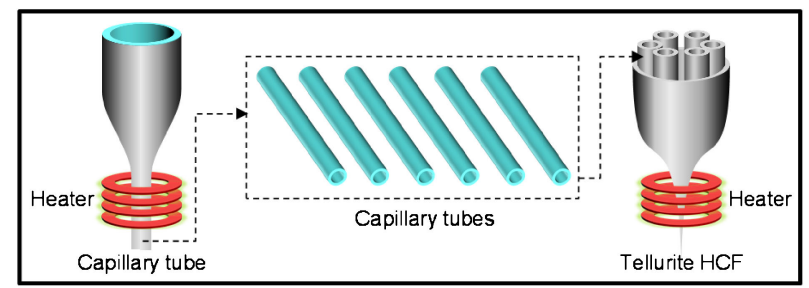

Fig. 10. Schematic diagram depicts the fiber fabrication of tellurite HCOF with a 6 non-touching cladding air-hole structure.

that the confinement loss of the touching air-hole structure is very high as compared to that of the non-touching structure, especially in the long wavelength range over $5.0 \mu \mathrm{m}$.

\subsection{Fiber fabrication}

Following the finding of the above numerical analysis, a tellurite HCOF with 6 non-touching air holes in the cladding was fabricated by using the stack-and-draw technique. Its fiber fabrication process is illustrated as the schematic diagram in Fig. 10. A cylindrical TZLB tube was first prepared by using rotational casting method. ${ }^{35)}$ Its outer and inner diameters were 15 and $10 \mathrm{~mm}$, respectively. The outer of the tube was polished so that its wall thickness was controlled to be as thin as $1 \mathrm{~mm}$. Then, it was elongated to obtain TZLB capillary tubes which have $0.25-\mathrm{mm}$ wall thickness. The length of each tube was about $15 \mathrm{~cm}$. A hexagonal air-hole structure in the cladding was formed by stacking and soldering a set of 6 capillary tubes inside a cylindrical TZLB jacket tube. Finally, they were drawn

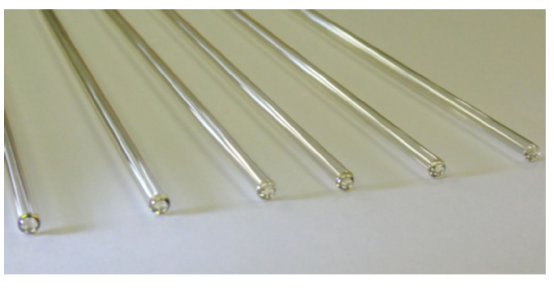

Capillary tubes

Fig. 11. Capillary tubes to obtain the tellurite HCOF in this work.

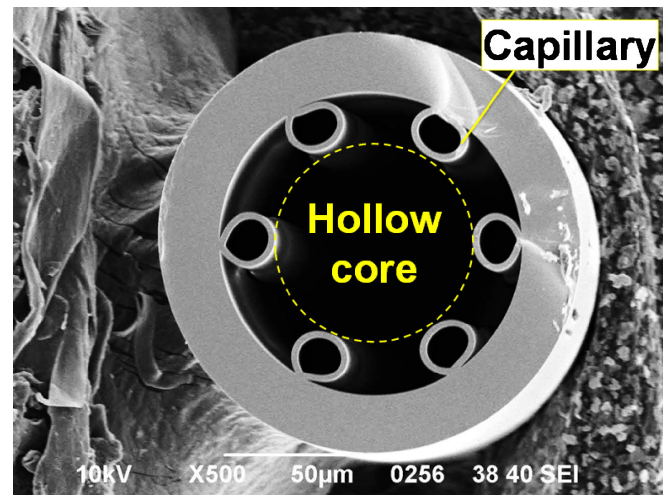

Fig. 12. Cross-sectional image of the fabricated tellurite $\mathrm{HCOF}$ taken by a scanning electron microscope.

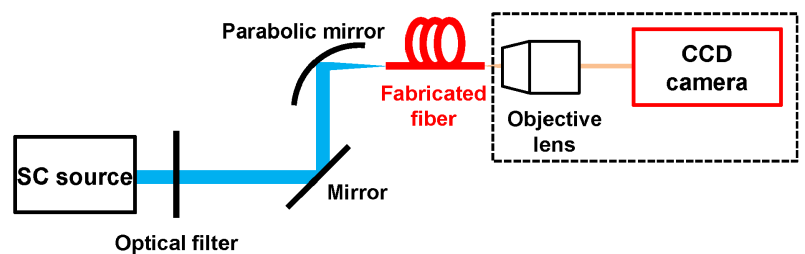

Fig. 13. Experimental setup for the mode intensity distribution measurement in the fabricated tellurite $\mathrm{HCOF}$.

into fiber whose diameter was about $150 \mu \mathrm{m}$. Experimental capillary tubes and the fiber cross-sectional image which was taken by a scanning electron microscope are shown in Figs. 11 and 12, respectively.

\section{Results and discussions}

A supercontinuum light source (Fianium SC450) was coupled into the central hollow core of a 20-cm-long fabricated tellurite HCOF by the butt-joint method. The images of propagated modes at the output facet of the fiber segment were captured by a near-infrared CCD camera as shown in Fig. 13.

By carefully controlling the coupling conditions such as the incident angle of light beams and incident intensity, the light can be coupled successfully into the hollow core of the fiber as the fundamental mode. Besides, the 1st order mode can also be found. The captured images of the modes propagated in the fiber were shown in Fig. 14. They are consistent with images which were obtained by the numerical calculation using the Comsol Multiphysics software as shown in Fig. 15. 


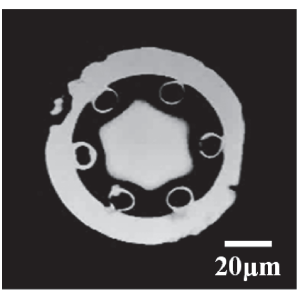

Fundamental mode

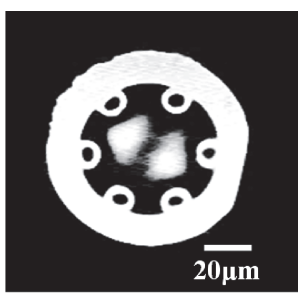

$1^{\text {st }}$ order mode

Fig. 14. Images of the propagated modes captured at the output facet of the fiber by using the CCD camera.

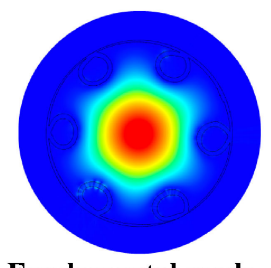

Fundamental mode $1^{\text {st }}$ order mode

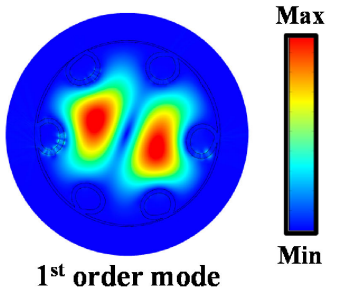

Fig. 15. Images of the propagated modes calculated by using FEM and PM boundary condition.

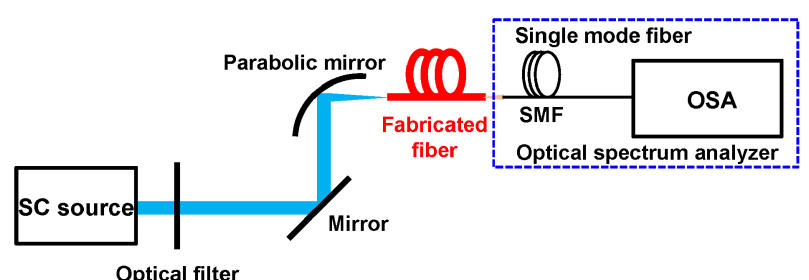

Fig. 16. Experimental setup for the transmission spectrum measurement in the fabricated tellurite HCOF.

To analyse the transmission properties of the fabricated tellurite $\mathrm{HCOF}$, the objective lens and the $\mathrm{CCD}$ camera in Fig. 13 were replaced by a ZBLAN single mode fiber (Fiber Lab ZSF-6) which connected to optical spectrum analyzers (OSA) as shown in Fig. 16.

The transmission spectrum at the output end of the fiber was captured by two OSA (Yokogawa AQ6373 and AQ6375) whose working ranges were from 0.4 to $1.2 \mu \mathrm{m}$ and from 1.2 to $2.4 \mu \mathrm{m}$, respectively. The results were combined and plotted in Fig. 17. It can be seen that the spectrum included high transmission bands and low transmission bands, alternately. A close correspondence was found between our experimental transmission results and the antiresonant reflecting optical waveguide model. ${ }^{36)}$ It is explained that when antiresonant reflection takes place, the light is confined in the core forming high transmission bands. Contrarily, the minimum of the narrow low transmission bands correspond to resonant wavelengths. The resonant reflection wavelength ${ }^{36)} \lambda_{\mathrm{RR}}$ can be calculated by using Eq. (2) where $t$ is the wall thickness, $n_{\text {glass }}$ is the refractive index of tellurite glass and $m$ is the integer.

$$
\lambda_{\mathrm{RR}}=\frac{2 t\left(n_{\text {glass }}{ }^{2}-n_{\mathrm{air}}{ }^{2}\right)^{1 / 2}}{m}
$$

Vertical dashed lines in Fig. 17 represent the position of resonant reflection wavelengths calculated by Eq. (2). At

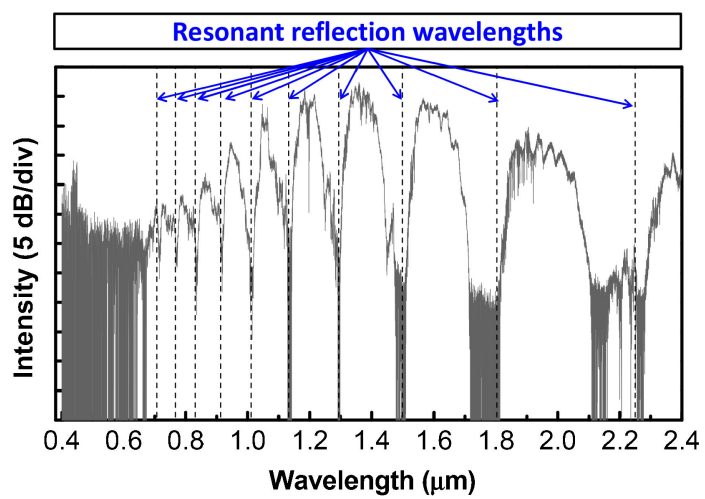

Fig. 17. Measured transmission spectrum after 20-mm-long segment of the fabricated fiber.

those wavelengths, the transmission drastically reduces and the transmission minima are found.

\section{Conclusions}

In this work, new tellurite HCOF which has 6 nontouching air holes in the cladding was studied. It is realized that when the two nearby cladding air-holes connect to each other, the confinement loss in the core will be high. The fiber fabrication of a tellurite HCOF with 6 nontouching cladding air holes was successfully carried out and the light propagation and transmission properties from 0.4 to $2.4 \mu \mathrm{m}$ were demonstrated experimentally for the first time. The transmission spectrum included high transmission bands and low transmission bands alternately due to the effect of resonant reflection and anti-resonant reflection. The measured results are consistent with the calculation. The results at longer wavelengths are expected in our future work, especially in the mid-IR region, in order to exploit this hollow core fiber for many potential applications.

Acknowledgements This work was supported by the Japan Society for the Promotion of Science (JSPS) KAKENHI (Grant Number 15H02250, 17K18891 and 18H01504) and the JSPS-CNRS joint research program.

\section{References}

1) P. Jaworski, F. Yu, R. R. J. Maier, W. J. Wadsworth, J. C. Knight, J. D. Shephard and D. P. Hand, Opt. Express, 21, 22742-22753 (2013).

2) P. Uebel, M. C. Gunendi, M. H. Frosz, G. Ahmed, N. N. Edavalath, J. M. Menard and P. S. J. Russell, Opt. Lett., 41, 1961-1964 (2016).

3) Z. F. Wang, W. Belardi, F. Yu, W. J. Wadsworth and J. C. Knight, Opt. Express, 22, 21872-21878 (2014).

4) F. Belli, A. Abdolvand, W. Chang, J. C. Travers and P. S. Russell, Optica, 2, 292-300 (2015).

5) M. I. Hasan, N. Akhmediev and W. Chang, Opt. Lett., 41, 5122-5125 (2016).

6) J. Anthony, R. Leonhardt, S. G. Leon-Saval and A. Argyros, Opt. Express, 19, 18470-18478 (2011).

7) A. N. Kolyadin, A. F. Kosolapov, A. D. Pryamikov, A. S. Biriukov, V. G. Plotnichenko and E. M. Dianov, 
Opt. Express, 21, 9514-9519 (2013).

8) J. D. Shephard, J. D. C. Jones, D. P. Hand, G. Bouwmans, J. C. Knight, P. S. Russell and B. J. Mangan, Opt. Express, 12, 717-723 (2004).

9) M. Duguay, Y. Kokubun, T. L. Koch and L. Pfeiffer, Appl. Phys. Lett., 49, 13-15 (1986).

10) C. L. Wei, R. J. Weiblen, C. R. Menyuk and J. Hu, $A d v$. Opt. Photonics, 9, 504-561 (2017).

11) W. Belardi and J. C. Knight, Opt. Express, 21, 2191221917 (2013).

12) W. Belardi and J. C. Knight, Opt. Lett., 39, 1853-1856 (2014).

13) W. Belardi and J. C. Knight, Opt. Express, 22, 1009110096 (2014).

14) M. S. Habib, J. E. Antonio-Lopez, C. Markos, A. Schulzgen and R. Amezcua-Correa, Opt. Express, 27, 3824-3836 (2019).

15) A. D. Pryamikov, A. S. Biriukov, A. F. Kosolapov, V. G. Plotnichenko, S. L. Semjonov and E. M. Dianov, Opt. Express, 19, 1441-1448 (2011).

16) J. C. Knight, J. Broeng, T. A. Birks and P. S. J. Russell, Science, 282, 1476-1478 (1998).

17) P. Russell, Science, 299, 358-362 (2003).

18) F. Yu and J. C. Knight, Opt. Express, 21, 21466-21471 (2013).

19) J. R. Hayes, S. R. Sandoghchi, T. D. Bradley, Z. X. Liu, R. Slavik, M. A. Gouveia, N. V. Wheeler, G. Jasion, Y. Chen, E. N. Fokoua, M. N. Petrovich, D. J. Richardson and F. Poletti, J. Lightwave Technol., 35, 437-442 (2017).

20) F. Poletti, N. V. Wheeler, M. N. Petrovich, N. Baddela, E. N. Fokoua, J. R. Hayes, D. R. Gray, Z. Li, R. Slavik and D. J. Richardson, Nat. Photonics, 7, 279-284 (2013).
21) W. L. Lu and A. Argyros, J. Lightwave Technol., 32, 4019-4025 (2014).

22) S. Atakaramians, A. Stefani, H. S. Li, M. S. Habib, J. G. Hayashi, A. Tuniz, X. L. Tang, J. Anthony, R. Lwin, A. Argyros, S. C. Fleming and B. T. Kuhlmey, J. Infrared Millim. Te., 38, 1162-1178 (2017).

23) A. Urich, R. R. J. Maier, F. Yu, J. C. Knight, D. P. Hand and J. D. Shephard, Biomed. Opt. Express, 4, 193-205 (2013).

24) A. Urich, R. R. J. Maier, F. Yu, J. C. Knight, D. P. Hand and J. D. Shephard, J. Non-Cryst. Solids, 377, 236-239 (2013).

25) F. Benabid, F. Couny, J. C. Knight, T. A. Birks and P. S. Russell, Nature, 434, 488-491 (2005).

26) A. M. Cubillas, S. Unterkofler, T. G. Euser, B. J. M. Etzold, A. C. Jones, P. J. Sadler, P. Wasserscheid and P. S. Russell, Chem. Soc. Rev., 42, 8629-8648 (2013).

27) T. Ritari, J. Tuominen, H. Ludvigsen, J. Petersen, T. Sorensen, T. P. Hansen and H. R. Simonsen, Opt. Express, 12, 4080-4087 (2004).

28) H. T. Tong, N. Nishiharaguchi, T. Suzuki and Y. Ohishi, J. Ceram. Soc. Jpn., 127, 187-190 (2019).

29) A. J. Werner, Appl. Optics, 7, 837-843 (1968).

30) W. S. Rodney, I. H. Malitson and T. A. King, J. Opt. Soc. Am. A, 48, 633-636 (1958).

31) B. Tatian, Appl. Optics, 23, 4477-4485 (1984).

32) M. I. Hasan, N. Akhmediev and W. Chang, J. Lightwave Technol., 36, 4060-4065 (2018).

33) C. L. Wei, C. R. Menyuk and J. Hu, IEEE Photonics J., 8, 1-9 (2016).

34) F. Poletti, Opt. Express, 22, 23807-23828 (2014).

35) A. Mori, J. Ceram. Soc. Jpn., 116, 1040-1051 (2008).

36) N. M. Litchinitser, A. K. Abeeluck, C. Headley and B. J. Eggleton, Opt. Lett., 27, 1592-1594 (2002). 